1814 y 1815 , a su postergación en los acuerdos de paz (culminados en el Congreso de Viena) y, en parte, e indirectamente, al inicio de su aislamiento de Europa durante el siglo XIX.

Por ello, esta obra ha pretendido recuperar para la historia, el esfuerzo decisivo militar español en el inicio de la derrota de la aventura napoleónica en Europa en 1812. $\mathrm{Y}$ en estos hechos, hay que dar a conocer y reseñar la actuación abnegada, constante y victoriosa de $\operatorname{los} 6^{\circ}$ y $7^{\circ}$ ejércitos españoles en el noroeste de la Península Ibérica entre 1810 y 1813.

\title{
Población, sociedad y familia en Tierra de Campos leonesa. La comarca de Sahagún en el s. XVIII.
}

\section{Francisco Javier LAGARTOS PACHO}

Director: Dr. Juan Manuel Bartolomé Bartolomé

Tesis Doctoral defendida el 21 de enero de 2016

Para el conocimiento de cualquier ámbito cultural humano del pasado es necesario analizar las estructuras de una sociedad, especialmente los parámetros demográficos y sociales, en nuestro caso, aquellos que tiene relación con la familia y su perpetuación en el tiempo. La familia, como la célula básica de una sociedad, comprende infinidad de ámbitos de estudio: herencia, relaciones de parentesco, consanguinidad, estrategias y alianzas matrimoniales, etc., que son necesarios entender para un buen conocimiento de la misma y de la sociedad en la que está inserta. El objetivo de esta investigación ha sido el de conocer, desde la perspectiva de la historia de la familia, cuales son las pautas demográficas y cómo se llevaba a cabo el entramado familiar para conseguir el objetivo final de toda sociedad que es la perpetuación del sistema.

La consecución de este objetivo se ha plasmado geográficamente en el sureste de la actual provincia de León, en concreto en la comarca de Sahagún, y en un espacio temporal que abarca, principalmente, el siglo XVIII. Es un territorio con características propias de las zonas geográficas de transición, es decir, presenta unas particularidades que le vienen dadas de la mezcla de los modelos limítrofes perfectamente definidos, en este caso, entre los territorios de las estribaciones de la montaña leonesa y la ribera del río Esla y las zonas llanas castellanas de lo que se conoce como Tierra de Campos vallisoletana y palentina. Con este estudio hemos desmontado una serie de estereotipos 
que se han ido asentando y que giran en torno, por ejemplo, a la localización geográfica o a la homogeneidad de los parámetros socio-demográfico y que se han demostrado falsos. Ha contribuido a extender esta imagen de indefinición geográfica, simplicidad y homogeneidad la escasez de estudios relacionados con los ámbitos sociales (familia, herencia) y económicos (subsistencia) cuyo eje vertebrador sean zonas de transición, más acentuada esta carencia en el sureste leonés. Con este estudio hemos superado el aspecto geográfico, territorial y nominativo a la vez que hemos introducido planteamientos historiográficos basados en el análisis del ámbito familiar y social de forma diferenciada sin que uno condicione la forma del otro.

Nuestra investigación se ha basado en tres grandes pilares fundamentales. Hemos analizado todo lo referente al conocimiento de la población y las características de los agregados domésticos para acercarnos al potencial demográfico de la zona. Estudiando la natalidad, mortalidad y nupcialidad, la cual, nos ha abierto el camino para comprender la formación, constitución y consolidación del matrimonio como uno de los conceptos claves de nuestro estudio.

Después hemos estudiado la estructura económica de las explotaciones agrarias, la propiedad agraria y su distribución, el aprovechamiento del terreno, etc. relacionándolo con la familia y el hogar. Esta sociedad desigual ante la que nos encontramos, nos aleja de esas idílicas comunidades de carácter igualitario, aunque bien es cierto que las diferencias entre los distintos grupos están menos marcadas en la comarca de Sahagún que otras regiones de la península. Estamos hablando de una sociedad compuesta por pequeños y medianos propietarios caracterizados por desarrollar estrategias laborales muy variadas, no dudando en utilizar los recursos disponibles, tanto materiales, humanos, como laborales, para conseguir la reproducción del sistema. Aunque la mayor parte de los individuos aparecen con ocupaciones muy definidas y determinadas, lo cierto es que es muy frecuente la combinación del trabajo en su reducida explotación agraria con el trabajo asalariado, principalmente en el campo, aunque también en algunos pequeños talleres, como pastores de los grandes rebaños o como sirvientes domésticos en las casas de los terratenientes, con el objetivo de conseguir un mayor bienestar familiar y una perpetuación en el tiempo y en el espacio de la unidad familiar. En todo este desarrollo jugará un papel importante la mujer, colaborando en muchos de los procesos económicos, y los hijos, ayudando en las tareas agrícolas o con un aporte económico exterior, es decir, podemos ver como la importancia de la familia es vital en todo este proceso. 
Y, por último, analizamos los mecanismos utilizados por los individuos de la zona para la reproducción social, deteniéndonos en la transmisión de las herencias (propiedad, oficios, bienes muebles e inmuebles, etc.), la organización de las alianzas familiares, las redes de relación, etc. en definitiva todos aquellos aspectos que nos pongan sobre las pista de la forma en la que se perpetúa el sistema de generación en generación. En la práctica hereditaria se impone el igualitarismo frente a otros mecanismo que intentan suavizarlo, como es el caso la mejora post mortem y las mandas testamentarias y legados, aunque su utilización es algo menor que en otras zonas. La importancia del control que supone su utilización se une la voluntad intencionada de dirigir la familia en un determinado sentido, aquel que el testador considere el más idóneo para conseguir el fin último: mantener o mejorar la posición social. Así, este tipo de recursos se convierten en algo muy utilizado cuando desean burlar el sistema igualitario castellano, posibilitando el aumento patrimonial de sus beneficiarios y provocando con ello el distanciamiento económico entre los diferentes miembros de una familia, según las diferentes estrategias seguidas por las jefaturas familiares.

Nuestro interés siempre fue el de llegar a un análisis más dinámico que nos ha llevado a comprender la desigualdad que se produce entre los diferentes hogares y la permanencia de la misma en el tiempo y en el espacio, centrándonos en los miembros de las ocupaciones agrarias (labradores, jornaleros y pastores), que representan dos tercios del total de efectivos de la zona. Entre jornaleros y pastores la tendencia es la juventud, viendo en esta salida profesional la incorporación al mercado laboral, ya que, apenas poseían una explotación agraria propia. Toda esta situación se invierte a partir de los 35-40 años y se acelera a partir de los 50-55 años a favor de los labradores, llegando a representar un número importante los labradores mayores de 70 años. Así, los asalariados se caracterizan por la transitoriedad en edades tempranas frente a la permanencia de su trabajo asalariado más allá de los 55-60 años, mientras que la disminución del número de jornaleros y la superioridad de los labradores a partir de los 40 y 55 años, respectivamente, es fruto de una movilidad socio-profesional entre ambos grupos. La situación social viene a ser otro elemento de cambio y está determinada, en gran parte, por la propiedad. La posición social en base a este parámetro puede variar en el tiempo, no permaneciendo inmutable a lo largo de la vida de un individuo, ya que existen múltiples mecanismos que modifican los niveles de propiedad y, en consecuencia, la pertenencia o no a un estrato social determinado, constatando en nuestra zona de estudio como el tipo de actividad desempeñada a lo largo de la vida y la edad del individuo están relacionadas con el número de 
propiedades agrarias que posee. De este modo, la ocupación agraria lleva consigo que los cabezas de familia vayan ascendiendo desde el punto vista económico, pero no ocurre así con otras profesiones como los jornaleros, que con mucho esfuerzo y con el paso del tiempo, llegarán a conformar pequeñas haciendas en base, principalmente, a dos actuaciones: por los aciertos económicos que se producen en el seno del propio hogar y por las prácticas hereditarias y el dirigismo familiar por medio del recibo de donaciones, de otras herencias de familiares cercanos como tíos/as solteros/as, curas, etc.

En definitiva, nuestro trabajo ha partido de los nuevos postulados teóricos acerca del estudio de la familia en el que, sin abandonar el análisis general tradicional, hemos intentado prestar mayor atención a los comportamientos diferenciales y a las prácticas sociales, donde el individuo no es contemplado como algo rígido sino como un actor pensante y director de sus destinos.

Con estas premisas metodológicas hemos conseguido aumentar nuestro conocimiento acerca de los aspectos familiares y su relación con el medio y la sociedad propia del siglo XVIII en la comarca de Sahagún, desentrañando los entresijos que determinan la formación, consolidación y el establecimiento de una nueva unidad familiar. Además, hemos puesto de manifiesto cómo se perpetuaban y reproducían las acusadas diferencias que encontramos en el mundo rural, poniendo en relación la familia y los recursos, a la vez que hemos dejado el tema abierto para futuras explicaciones de acontecimientos o para posteriores ampliaciones de los aspectos familiares cotidianos y su relación con el medio y la sociedad propia del siglo XVIII en Tierra de Campos leonesa.

Con todo ello, en nuestro estudio hemos intentado aproximarnos a la familia terracampina partiendo de su análisis bajo tres parámetros fundamentales: hogar, trabajo y explotación agraria y su transmisión, como metodología para explicar los cimientos y componentes del funcionamiento del sistema social. De este modo, hemos interrelacionado el agregado doméstico con la explotación agraria, sobre la cual hemos situado los diferentes grupos sociales en base a unos parámetros prefijados con anterioridad. 